\title{
Use of stents in patients undergoing chemotherapy for borderline resectable pancreatic cancer-causing biliary obstruction while awaiting surgery: A cost-effectiveness analysis
}

(1) $\odot \ominus$

\author{
Authors \\ Institutions \\ 1 Division of Gastroenterology, McGill University Health \\ Centre, McGill University, Montréal, Québec, Canada \\ 2 Division of Gastroenterology, King Khalid University \\ Hospital, King Saud University, Riyadh, Saudi Arabia \\ 3 Section of Gastroenterology and Hepatology, \\ Dartmouth-Hitchcock Medical Center, Lebanon, New \\ Hampshire, United States \\ 4 Department of Surgery, McGill University Health Centre, \\ McGill University, Montréal, Québec, Canada
}

Majid A. Almadi ${ }^{1,2}$, Timothy B. Gardner ${ }^{3}$, Yen-I Chen ${ }^{1}$, Viviane Adam¹, Jeffrey Barkun ${ }^{4}$, Alan Barkun ${ }^{1}$

\section{ABSTRACT} sus metal biliary stenting in this setting. submitted 25.11.2020

accepted after revision 20.4.2021

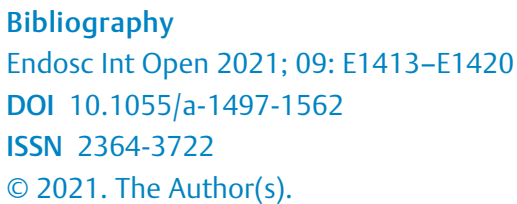

This is an open access article published by Thieme under the terms of the Creative Commons Attribution-NonDerivative-NonCommercial License, permitting copying and reproduction so long as the original work is given appropriate credit. Contents may not be used for commercial purposes, or adapted, remixed, transformed or built upon. (https://creativecommons.org/licenses/by-nc-nd/4.0/)

Georg Thieme Verlag KG, Rüdigerstraße 14,

70469 Stuttgart, Germany

Corresponding author

Dr. Alan N. Barkun, McGill University and the McGill University Health Centre, 1650 Cedar Avenue, D7.346, Montréal, Québec, Canada, H3G1A4

Fax: +1-514-934-8547

alan.barkun@muhc.mcgill.ca

Supplementary material is available under https://doi.org/10.1055/a-1497-1562
Background and study aims Biliary stenting is indicated to relieve obstruction from borderline resectable pancreatic cancer while patients receive preoperative neoadjuvant therapy. We compared the cost-effectiveness of plastic ver-

Methods A decision tree analysis compares two competing types of biliary stents (initially metal vs. initially plastic) to treat malignant distal biliary obstruction while receiving neoadjuvant therapy with different scenarios including possible complications as bridge till the patient undergoes curative surgical attempt. Using published information, effectiveness was chosen as the probability of successfully reaching a state of being ready for surgery once chemotherapy was completed. Costs (2018US\$) were based on national data. A third-party payer perspective was adopted, and sensitivity analyses were performed over a time-horizon of one year.

Results Initially inserting a metal versus a plastic biliary stent was more efficacious with a higher probability of reaching the readiness for surgery endpoint ( $96 \%$ vs. $85 \%$ ), on average 18 days earlier while also being less expensive (US\$9,304 vs. US\$11,538). Sensitivity analyses confirmed robustness of these results across varying probability assumptions of plausible ranges and remained a dominant strategy even when lowering the willingness-to-pay threshold to US\$1,000.

Conclusions Initial metal stenting to relieve malignant biliary obstruction from borderline resectable pancreatic cancer in patients undergoing neoadjuvant therapy prior to surgery is a dominant intervention in economic terms, when compared to initially inserting a plastic biliary stent as it results in a greater proportion of patients being fit for surgery earlier and at a lower cost.

\section{Introduction}

The burden of pancreatic cancer has increased over the last decade with a present age-standardized incidence of 5.7 per 100,000 person-years and an estimated 441,000 deaths global- ly [1]. Pancreatic cancer has a low 5-year survival rate of only 9.3\% based on the United-States Surveillance, Epidemiology, and End Results program [2]. Surgery represents the only modality to achieve cure and, unfortunately, a majority of patients present at an advanced stage when it is no longer an option. 


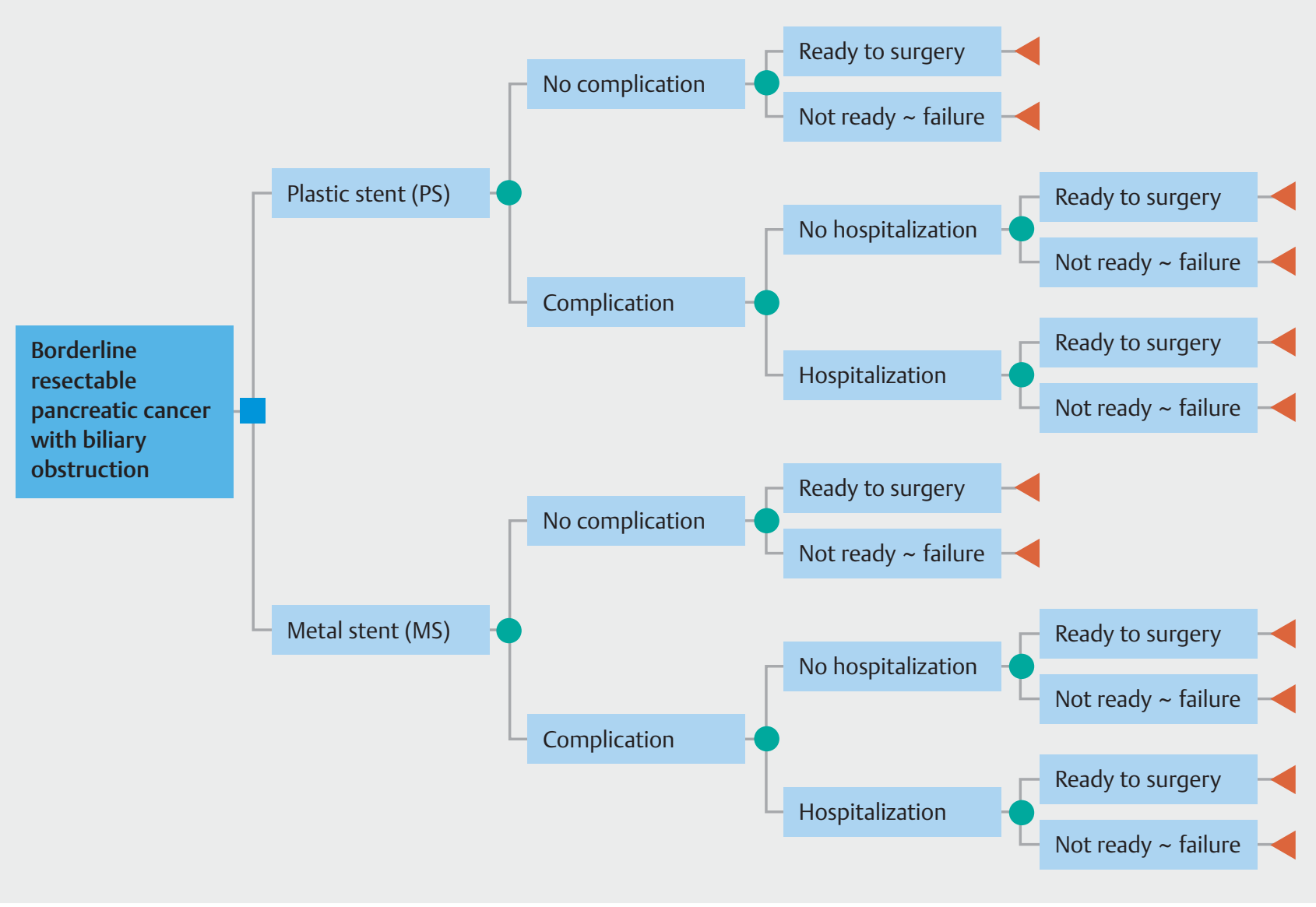

Fig. 1 Decision model structure.

Once biliary obstruction and jaundice due to pancreatic cancer develops, stenting is indicated for palliation [3]; in this context, the superiority of metal over plastic biliary stents has been demonstrated [4, 5] as cost-effectiveness [6-8].

More recently, the use of neoadjuvant therapy prior to surgery has been advocated in cases of resectable and borderline resectable pancreatic cancer [9]. The aims of such therapy are earlier treatment of micro-metastatic disease, better tolerance of systemic therapy prior to surgery, improved selection of patients without rapidly progressive disease for surgical resection, as well as lower rates of positive resection margins $[10,11]$.

In these patients, the increased upfront costs of metal biliary stenting needs to be weighed against any possible costs of increased complications due to the shorter stent patency duration of plastic stents with resulting interruptions in the chemotherapy protocol leading to a delay or cancellation of subsequently planned surgery. Based on available literature, there exists uncertainty as to the cost-effectiveness of metal versus plastic stents for biliary drainage in the setting of neoadjuvant therapy. Indeed, some studies have suggested the superiority of initially inserting a metal biliary stent in this setting [1215], while a retrospective study from Japan showed no difference in the effectiveness of both stents [16], and a US randomized controlled trial (RCT) demonstrated similar cost-effectiveness comparing both approaches [17]. We thus aimed to better characterize the cost-effectiveness of initial plastic versus metal biliary stent placement in patients with a resectable or borderline resectable pancreatic cancer causing biliary obstruction in whom pre-operative neoadjuvant therapy is planned.

\section{Methods}

\section{Model design and patient population}

The decision analysis software TreeAge Pro 2018 (Williamstown, Massachusetts, United States) was used to design a decision tree ( $\triangleright$ Fig. 1) comparing two competing types of stents to treat malignant distal biliary obstruction. The target population was adult patients with borderline resectable pancreatic cancer. Possible clinical management scenarios following the insertion of the biliary stent were included in the model. The overall time horizon was up to 1 year, with the duration of successive specific health states leading to respective terminal nodes for each approach that are based on available data from the literature. If there was no complication at any time after the initial stent insertion at index endoscopic retrograde cholangiopancreatography (ERCP), the patient ended the planned chemotherapy and reached the terminal node identifying the individual as ready for the surgery or not, also noting the time elapsed between initial stent insertion and this decision. For the patient who suffered a complication following initial stent insertion, 
the model then included a possible admission. In such a patient, a second ERCP was performed and the original stent was replaced by a metal expandable stent (fully or partially covered), regardless of the type of initial stent that was inserted (metal or plastic). The patient then proceeded to the terminal node of either "ready for surgery" or "not ready for surgery" based on the observed outcomes for such patients as reported in studies identified by our comprehensive literature review. In the former case, the time elapsed to reach this decision from initial stent insertion also was tabulated. The model assumed chemotherapy and follow-up of the patient every 15 days throughout the process until the final health status (when the patient reaches the terminal node). If there was an admission, chemotherapy was suspended during the hospital length-ofstay and was restarted again 1 week after the end of hospitalization.

\section{Outcomes of effectiveness}

The primary outcome of effectiveness was the cumulative probability for each strategy across all its possible clinical paths with which the patient is deemed a surgical candidate (i.e.: after having completed chemotherapy and repeat staging), or not. The secondary outcome of effectiveness was the mean time in days elapsed between initial stent insertion and a decision that the patient was indeed ready for surgery, if that was the case. Death was not considered in the model as there exist no data to suggest that either stenting strategy provides a survival benefit [12-17].

\section{Data sources and analytical framework}

A comprehensive literature search was performed from 1978 to February 2019 using OVID MEDLINE, EMBASE, Cochrane Library, and ISI Web of Knowledge databases with validated search terms specified for pancreatic cancer and stenting (Appendix 1). Additional relevant studies were identified from cross-referencing and hand-searches of references of the retrieved articles. All human adult studies published in English were considered.

The computed average duration of management from initial stent insertion until the final reassessment of the patient for surgery following chemotherapy was based on the mean duration (in days) of those patients who enrolled in a prospective randomized study [17] and reached this desired endpoint. All probabilities are derived from the literature.

National mean hospital costs and length-of-stay are provided by the National Inpatient Sample 2015 which is a US-wide database collecting more than 7 million hospitalization records across 47 states. Hospitalizations of adult patients identified with the ICD-9-CM code '576.1' (cholangitis - used as it is the most common complication noted requiring admission, which also usually has the most consequential length of stay and impact amongst all possible complications in this setting on subsequent time to readiness for surgery) are selected to represent the hospitalisations in the model. Physician fees and drug prices are the national amounts provided by Centers for Medicare and Medicaid Services 2018. For chemotherapy drug costs, the respective average body surface of patients for an upper gastro- intestinal category is used, weighted by the proportion of individuals developing pancreatic cancer in North America in 2016 [18]. Stent prices and ERCP facility fees were provided by Boston Scientific Inc. (Marlborough, Massachusetts, United States).

The willingness-to-pay (WTP) threshold is defined as the pre-fixed maximum dollar value that is deemed acceptable spending for a treatment for biliary obstruction in borderline resectable pancreatic cancer. It is fixed at US\$50,000 as previously done in such analyses [6,19-21]. Adopting a third-party payer perspective, only direct costs were considered. All costs are expressed in 2018 US\$ using, when necessary, the US consumer price index for medical services.

\section{Presentation of results}

Results were reported as average costs, effectiveness, and costeffectiveness ratios per individual treatment. The effectiveness measure used in reporting cost-effectiveness was the probability of being ready for surgery once chemotherapy was completed. One-way deterministic sensitivity analysis, including Tornado analyses, was performed on all the variables of the model. Possible relevant tipping points beyond the variable bounds identified by threshold analyses are presented.

A probabilistic sensitivity analysis also was performed, exploring further the uncertainty around the point estimates. The Monte-Carlo analysis runs 100,000 simulations varying simultaneously all model assumptions across their respective ranges. The resulting cost-effectiveness acceptability curve graph and scatter plot graph including the incremental cost-effectiveness report were generated. The reporting of our results followedthe CHEERS Statements recommendations (http:// www.resource-allocation.com/content/11/1/6).

\section{Results}

\section{Reported variables and their determination}

The search string used to identify the relevant studies is included in Appendix. Twenty-six input variables were required to construct the model ( $\downarrow$ Table 1$)$ ). Probabilities were extracted from six studies [12-17]. Drug chemotherapy costs were based on the Folforinox regimen (oxaliplatin, leucovorin, irinotecan, fluorouracil [22]). Costs for metal stenting represent a weighted average of biliary fully covered (80\%) and uncovered (20\%) metal stents. The range around the point estimate for each variable was set at $\pm 30 \%$ of its respective baseline value and the WTP was fixed at US\$50,000. We associated $\beta$ distributions to probabilities and normal distributions to the length of the chemotherapy cycles, delays of suspension after the end of hospitalization, and frequency of follow-up throughout the process until the terminal nodes, while $y$ distributions were applied for all other variables [23].

The cost-effectiveness analysis ( $\downarrow$ Table 2 ) suggests that choosing a metal stent at the initial insertion is associated with an average cost per patient of US\$9,304 across an average length of clinical management of 170 days, yielding a $96 \%$ probability for the patient to eventually be ready for surgery. The initial plastic stent option is associated with both a more 
- Table 1 Model assumptions.

\begin{tabular}{|c|c|c|c|c|c|c|}
\hline Category & Description & Baseline & Units & Low & High & $\begin{array}{l}\text { Source (Ref } \\
\text { Number) }\end{array}$ \\
\hline Probability & Admission if complication post initial insertion & 39.024 & $\%$ & 27 & 51 & Literature [15] \\
\hline Probability & Complication (MS) & 23.809 & $\%$ & 16 & 31 & Literature [12-17] \\
\hline Probability & Complication (PS) & 71.429 & $\%$ & 50 & 93 & Literature [12-17] \\
\hline Probability & Being ready for surgery if complication (MS) & 83.333 & $\%$ & 58 & 100 & Literature [12-17] \\
\hline Probability & Being ready for surgery if complication (PS) & 78.667 & $\%$ & 55 & 100 & Literature [12-17] \\
\hline Probability & Being ready for surgery if no complication (MS) & 100 & $\%$ & 70 & 100 & Literature [12-17] \\
\hline Probability & Being ready for surgery if no complication (PS) & 100 & $\%$ & 70 & 100 & Literature [12-17] \\
\hline Percentage & Distribution of fully-covered/uncovered for MS & 80 & $\%$ & 56 & 100 & $\begin{array}{l}\text { Expert author con- } \\
\text { sensus }\end{array}$ \\
\hline Physician fees & Anesthesia & 221.89 & 2018 US\$ & 155 & 289 & CMS \\
\hline Physician fees & Inpatient consultation & 76 & 2018 US\$ & 53 & 99 & CMS \\
\hline Physician fees & Outpatient consultation & 69 & 2018 US\$ & 48 & 90 & CMS \\
\hline Physician fees & ERCP first insertion & 488.69 & 2018US\$ & 342 & 636 & CMS \\
\hline Physician fees & ERCP second insertion & 510.11 & 2018US\$ & 357 & 664 & CMS \\
\hline Physician fees & Inpatient follow-up & 39.96 & 2018 US\$ & 27 & 52 & CMS \\
\hline Physician fees & Patient visits (outside initial ERCP and any admission) & 79.90 & 2018 US\$ & 55 & 104 & CMS \\
\hline Price per cycle & Neoadjuvant chemotherapy ${ }^{1}$ & 170.17 & 2018 US\$ & 119 & 222 & CMS \\
\hline Procedure fees & Endoscopic Retrograde Cholangio-Pancreatography & 1,849 & 2018 US\$ & 1,294 & 2,404 & $\begin{array}{l}\text { Boston Scientific } \\
\text { Inc. }\end{array}$ \\
\hline Unit price & Fully covered MS ( 10 French $\times 60 \mathrm{~mm})$ & 2,400 & 2018 US\$ & 1,680 & 3,120 & $\begin{array}{l}\text { Boston Scientific } \\
\text { Inc. }\end{array}$ \\
\hline Unit price & $\mathrm{PS}(10 \mathrm{~F} \times 70 \mathrm{~mm})$ & 105 & 2018 US\$ & 73 & 137 & $\begin{array}{l}\text { Boston Scientific } \\
\text { Inc. }\end{array}$ \\
\hline Unit price & Uncovered MS ( $10 \mathrm{~F} \times 60 \mathrm{~mm})$ & 1,600 & 2018 US\$ & 1,120 & 2,080 & $\begin{array}{l}\text { Boston Scientific } \\
\text { Inc. }\end{array}$ \\
\hline Per diem & $\begin{array}{l}\text { Hospitalization for procedure or stent-related compli- } \\
\text { cation }\end{array}$ & $2,961.19$ & 2018 US\$ & 2,072 & 3,850 & NIS \\
\hline Duration & $\begin{array}{l}\text { Length-of-stay for procedure or stent-related compli- } \\
\text { cation NIS2015 }\end{array}$ & 4.9 & Days & 3 & 6 & NIS \\
\hline Duration & Chemotherapy cycle & 15 & Days & 10 & 20 & $\begin{array}{l}\text { Expert author con- } \\
\text { sensus }\end{array}$ \\
\hline Duration & $\begin{array}{l}\text { Delay in chemotherapy after hospitalization (post- } \\
\text { ponement) }\end{array}$ & 7 & Days & 5 & 9 & $\begin{array}{l}\text { Expert author con- } \\
\text { sensus }\end{array}$ \\
\hline Duration & Frequency of follow-up & 15 & Days & 10 & 20 & $\begin{array}{l}\text { Expert author con- } \\
\text { sensus }\end{array}$ \\
\hline
\end{tabular}

MS, metal biliary stent; ERCP, endoscopic retrograde cholangiopancreatography; PS, plastic biliary stent; CMS, Centers for Medicare and Medicaid Services; NIS, National Inpatient Sample (Healthcare Cost and Utilization Project).

${ }^{1}$ For a typical adult patient with borderline resectable pancreatic cancer with a body-surface area of $1.79 \mathrm{~m}^{2}$.

expensive average cost per patient of US\$11,538 and a lower effectiveness of $85 \%$ (in the probability of reaching the readiness for surgery outcome), while achieving this endpoint, on average, 18 days later. The initial metal stent option therefore dominates the initial plastic stent approach, being both less costly and more effective.
The Tornado diagram shows that the model is sensitive to some specific variables (hospitalization costs for procedure or stent-related complication, and a number of probabilities including the readiness for surgery after complications, of complications following plastic stent insertion, and of hospitalization). More specifically, the one-way sensitivity analysis shows 
- Table 2 Cost-effectiveness analysis report.

\begin{tabular}{|l|l|l|l|l|l|}
\hline Strategy & $\begin{array}{l}\text { Cost } \\
\text { (2018US\$) }\end{array}$ & $\begin{array}{l}\text { Incremental cost } \\
\text { (2018US\$) }\end{array}$ & Effectiveness & $\begin{array}{l}\text { Incremental } \\
\text { effectiveness }\end{array}$ & $\begin{array}{l}\text { Cost-effectiveness } \\
\text { ratio (2018US\$) } \\
\text { (CER) }\end{array}$ \\
\hline $\begin{array}{l}\text { Metal stent } \\
\text { (MS) }\end{array}$ & 9,304 & 0.9603 & 9,689 \\
\hline $\begin{array}{l}\text { (2018 US\$) } \\
\text { Plastic stent }\end{array}$ & 11,538 & 2,233 & 0.8476 & -0.1127 & 13,612 \\
\hline
\end{tabular}

- Table 3 Threshold values analysis.

\begin{tabular}{|c|c|c|c|c|c|}
\hline \multirow{2}{*}{$\begin{array}{l}\text { Variables } \\
\text { Unit price of fully-covered MS }\end{array}$} & \multirow{2}{*}{$\begin{array}{l}\text { Units } \\
\text { 2018 US\$ }\end{array}$} & \multirow{2}{*}{$\begin{array}{l}\begin{array}{l}\text { Baseline val- } \\
\text { ue }\end{array} \\
2,400\end{array}$} & \multicolumn{3}{|c|}{ Threshold value and resulting interpretation } \\
\hline & & & Above & 6,333 & $\begin{array}{l}\text { PS is still less effective but becomes } \\
\text { less expensive than MS }\end{array}$ \\
\hline Per diem hospitalization cost & 2018 US\$ & 2,961 & Below & 508 & $\begin{array}{l}\text { PS is still less effective but becomes } \\
\text { less expensive than MS }\end{array}$ \\
\hline Unit price of uncovered MS & 2018 US\$ & 1,600 & Above & 17,774 & $\begin{array}{l}\text { PS is still less effective but becomes } \\
\text { less expensive than MS }\end{array}$ \\
\hline $\begin{array}{l}\text { Length-of-stay for procedure or stent-related } \\
\text { complication hospitalization }\end{array}$ & days & 5 & Below & 1 & $\begin{array}{l}\text { PS is still less effective but becomes } \\
\text { less expensive than MS }\end{array}$ \\
\hline Complication rate (post initial MS) & $\%$ & 24 & Above & 48 & $\begin{array}{l}\text { PS is still less effective but becomes } \\
\text { less expensive than MS }\end{array}$ \\
\hline Complication rate (post initial PS) & $\%$ & 71 & Below & 48 & $\begin{array}{l}\text { PS is still less effective but becomes } \\
\text { less expensive than MS }\end{array}$ \\
\hline $\begin{array}{l}\text { Probability of being ready for surgery after a } \\
\text { complication (MS) }\end{array}$ & $\%$ & 83 & Below $^{1}$ & 36 & $\begin{array}{l}\text { PS becomes more effective but is } \\
\text { still more expensive than MS }\end{array}$ \\
\hline
\end{tabular}

that if the probability of reaching the health state of being ready for surgery after a complication following the initial stent insertion exceeds $94.5 \%$ in the initial plastic stent group or if this same probability in the case of no complication decreases below $85.2 \%$ in the metal stent group, an initial plastic stent insertion approach remains more expensive but becomes more effective than initial metal stenting. Across all other variations of assumption estimates ( $\downarrow$ Table 1 ), initial metal stent insertion always remains the dominant strategy.

In our baseline scenario, the patients who suffer no complication after insertion are all considered ready for surgery if they remain alive until then. However, when assessing theoretical variability in this assumption, deterministic sensitivity analysis demonstrates that if the probability of being ready after no complication remains above $79.2 \%$, initial metal stents are still preferred because of the additional costs associated to an initial plastic stent insertion strategy.

- Table 3 lists possible threshold values beyond our adopted variable ranges (that may or not be clinically plausible), identifying possible scenarios for when an initial metal stent choice becomes no longer dominant, with the relevant changes in cost and/or effectiveness results. Although initial metal stenting is no longer dominant, it is still the preferred strategy, considering a baseline a priori WTP set at US\$50,000.

Probabilistic analysis confirms the robustness of the results across a broad range of assumptions with much more favourable cost-effective ratios provided by initial metal stent insertion. The cost-effectiveness acceptability curve ( $\boldsymbol{\nabla}$ Fig. 2 ) shows that whatever the value of WTP, there is a strong likelihood that an initial metal stent is the preferred strategy when compared to the plastic alternative. Indeed, even if the WTP were to be as low as US\$1,000, there would still remain an $86 \%$ probability favouring the initial metal stent approach. The cloud diagram further confirms the robustness of the findings with metal stents dominating plastic stents in $81 \%$ of the 100,000 iterations modelled for ( $\triangleright$ Fig. 3 ).

\section{Discussion}

Self-expandable metal stents (SEMS) demonstrate longer patency duration and a lower rate of dysfunction than plastic stents; however, most studies have addressed the sole pallia- 


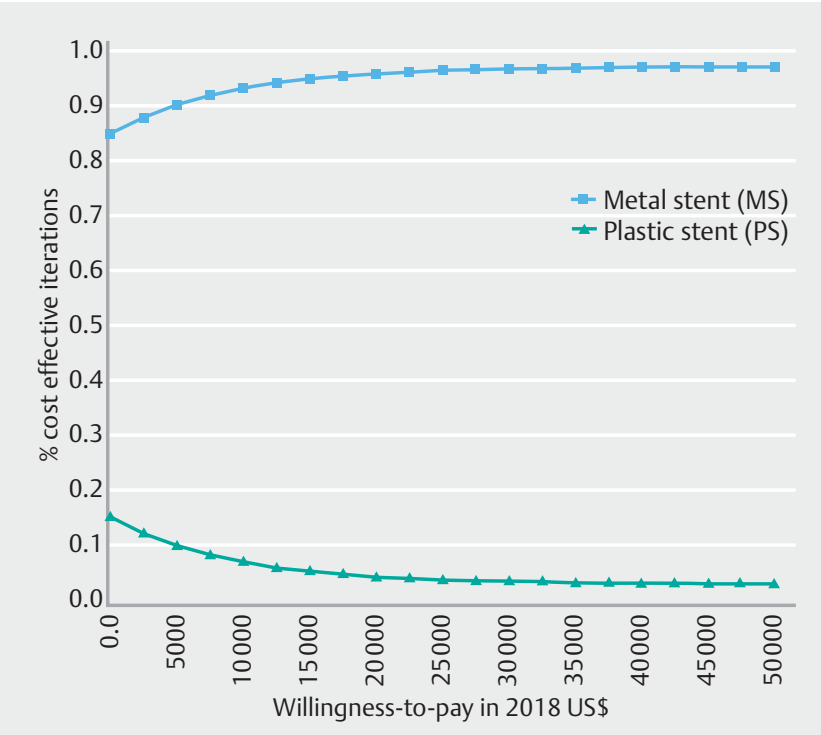

Fig. 2 Cost-effectiveness acceptability curve.

tion of patients with malignant distal biliary obstruction [24, 25]. In contradistinction, there still exists controversy as to which initial stent technology should be chosen in patients with biliary obstruction undergoing chemotherapy pre-operatively for pancreatic cancer $[26,27]$. Adding to the equipoise between initially using metal or plastic stents during neo-adju- vant chemotherapy is the suggestion that stent-related complications may in fact not impact significantly on resectability [14]. Even within the metal stent technology, the optimal choice of a covered vs uncovered prosthesis remains unclear $[4,28]$ although most societies now recommend a short fully covered self-expanding metal stent in cases of distal malignant biliary obstruction as a bridge to surgery while neoadjuvant therapy is administered [3,29-31]. The controversy about the optimal stent approach is further compounded by the high upfront costs of metal versus plastic biliary stenting and the disparate results reported in the literature [12-17]. We therefore performed a cost-effectiveness analysis to address this important clinical question, which is especially timely given the increasing volumes in oncological pancreatic surgery [32].

Our analysis demonstrates that initial insertion of a metal stent is a dominant economic strategy that is not only cost-effective due to its lower overall attributable costs (US\$9,304 vs. US\$11,538) but is also associated with a higher probability of reaching the all-important clinical outcome of readiness for surgery ( $96 \%$ vs. $85 \%$ ) and it does so 18 days earlier, an additional benefit that may further favor subsequent oncological outcomes for which we could not model. Strengths of the model include a broad sampling of available RCT and observational data, thus increasing generalizability of the results [12-17]. The choice of primary outcome of a patient being "ready for surgery" is the clinically most relevant endpoint, especially in the absence of reliable quality-of-life measurements applicable to the patient population in the preoperative period. We mod-

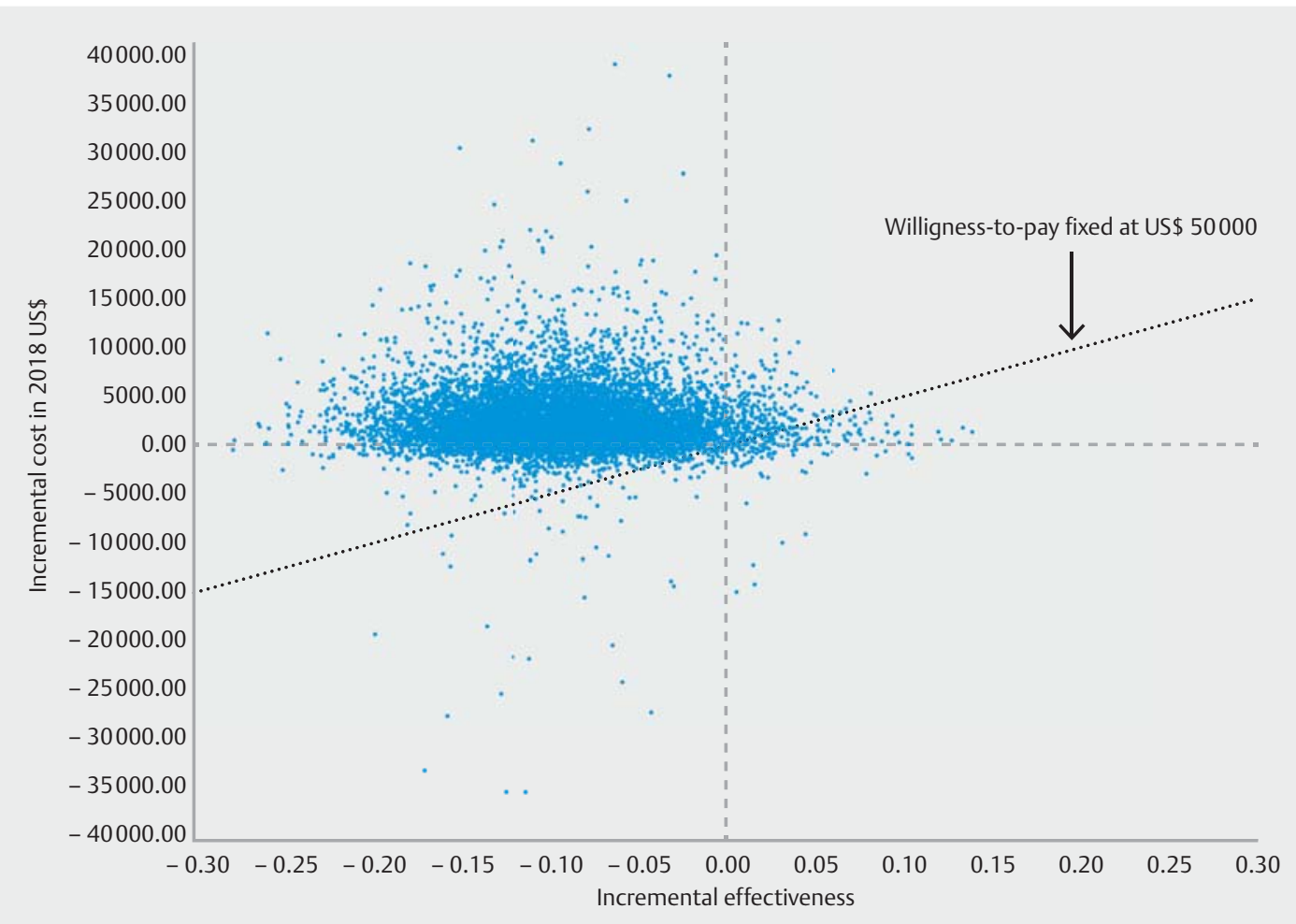

- Fig. 3 Incremental cost-effectiveness scatter plot of initial plastic stent versus metal stent strategy. The point (0:0), represents the MS as the strategy of reference. The dots represent the PS strategies for the simulations of the Monte-Carlo iterations. 
eled for the possible development of cholangitis as representative of procedure- or stent-related complications as it is the principal complication related to stent dysfunction requiring hospitalization with its subsequent very significant usual impact on costs and time-delay to being ready for surgery [26, 27]. Death was not considered due to the difficulty in assigning a cost to this health state and the realization that there is no reason to anticipate a difference in this outcome between adopted strategies based on existing comparative data.

Costs are based on representative updated national recent US information updated by the national consumer price index for 2018. As an assessment of validity, our estimation for hospitalization costs of cholangitis (reflecting procedure or stentrelated complications) are in accordance with those of other groups [12]. The time horizon of 12 months (which did not exceed 10 months in the model) was chosen as it is specifically adapted to the clinical situation, based on the best available data carefully collected in recent controlled settings [17], though it is probably longer that what would be usually planned as a time period for receiving neoadjuvant therapy, even if the chemotherapeutic regimens vary in the literature [33]. The strategy of replacing a dysfunctional plastic by a metal stent reflects what was done in some studies [17] but perhaps even more importantly provides a conservative estimate of effectiveness, optimizing stent patency in the initial plastic group $[4,34]$.

Our final results remain robust after extensive one-way and probabilistic sensitivity analyses testing with essentially unaltered conclusions across a broad range of clinically plausible ranges for all input cost and effectiveness variables. Most interestingly, this analysis demonstrated that the use of metal stents remains a dominant strategy even when the WTP threshold is decreased from a usual baseline assumption of US\$50,000 in such analyses $[6,19,20]$ to a much lower level of US\$1,000. It is estimated that the average WTP threshold value for middle to high income countries may range from US $\$ 2,307$ to US\$ 9,028 [35]. The conclusions, therefore, appear to be generalizable to many health care settings other than those in the US health care environment. Importantly, even though there exist disparate approaches to the optimal chemotherapeutic regimen favored among adult patients with borderline resectable pancreatic cancer, our point estimates and ranges, which capture most adopted regimens, coupled with the broad sensitivity analyses, allow us to capture such variation and provide results that remain robust even in the presence of lack of consensus opinion.

Limitations of this work include the variability of source data that the assumptions are based on, as well as not adopting possible alternate case-scenarios that would include replacing a plastic stent by another or solely cleaning a blocked metal stent. In all cases, the robustness of the sensitivity analyses is reassuring and make any different conclusions unlikely. The adopted unit of effectiveness represents a compromise in the absence of quality-of-life adjusted information in this specific patient population over the adopted time horizon. Chemotherapy-related complications were not modeled for as there is no a priori reason to believe that these would affect one stent group more than the other, thus not altering incremental effectiveness of cost estimates.

\section{Conclusions}

In conclusion, this study demonstrates the economic dominance of an approach of initial metal biliary stenting in patients undergoing preoperative neoadjuvant chemotherapy for borderline resectable pancreatic cancer when compared to initial plastic stent insertion. Such an approach results in greater effectiveness as measured by a higher probability of readiness for surgery at an earlier time and at decreased cost, over a broad range of assumptions.

\section{Competing interests}

Dr. Barkun is a consultant for Olympus Canada Inc. Dr. Yen-I Chen is a consultant for Boston Scientific.

\section{Funding}

The authors extend their appreciation to the International Scientific Partnership Program ISPP at King Saud University for funding this research work through ISPP-21-156(1)

References

[1] GBD 2017 Pancreatic Cancer Collaborators. The global, regional, and national burden of pancreatic cancer and its attributable risk factors in 195 countries and territories, 1990-2017: a systematic analysis for the Global Burden of Disease Study 2017. Lancet Gastroenterol Hepatol 2019; 4: 934-947

[2] Howlader N, Noone AM, Krapcho M et al. SEER Cancer Statistics Review, 1975-2016, National Cancer Institute. Bethesda, MD: https:// seer.cancer.gov/csr/1975_2016/ [based on November 2018 SEER data submission, posted to the SEER web site, April 2019]

[3] National Comprehensive Cancer Network. Pancreatic Adenocarcinoma (Version 1.2020). 2020: https://www.nccn.org/professionals/ physician_gls/pdf/pancreatic.pdf

[4] Almadi MA, Barkun AN, Martel M. No benefit of covered vs uncovered self-expandable metal stents in patients with malignant distal biliary obstruction: a meta-analysis. Clin Gastroenterol Hepat 2013; 11: $27-$ 37

[5] Sawas T, Al Halabi S, Parsi MA et al. Self-expandable metal stents versus plastic stents for malignant biliary obstruction: a meta-analysis. Gastrointest Endosc 2015; 82: 256-267

[6] Barkun AN, Adam V, Martel M et al. Partially covered self-expandable metal stents versus polyethylene stents for malignant biliary obstruction: a cost-effectiveness analysis. Canadian J Gastroenterol Hepatol 2015; 29: 377-383

[7] Kahaleh M, Brock A, Conaway MR et al. Covered self-expandable metal stents in pancreatic malignancy regardless of resectability: a new concept validated by a decision analysis. Endoscopy 2007; 39 : 319-324

[8] Martinez JM, Anene A, Bentley TG et al. Cost effectiveness of metal stents in relieving obstructive jaundice in patients with pancreatic cancer. J Gastrointest Cancer 2017; 48: 58-65 
[9] Heinrich S, Besselink M, Moehler M et al. Opinions and use of neoadjuvant therapy for resectable, borderline resectable, and locally advanced pancreatic cancer: international survey and case-vignette study. BMC Cancer 2019; 19: 675

[10] Mokdad AA, Minter RM, Zhu H et al. Neoadjuvant therapy followed by resection wersus upfront resection for resectable pancreatic cancer: A propensity score matched analysis. J Clin Oncol 2017; 35: 515-522

[11] Perez K, Clancy TE, Mancias JD et al. When, what, and why of perioperative treatment of potentially curable pancreatic adenocarcinoma. J Clin Oncol 2017; 35: 485-489

[12] Tsuboi T, Sasaki T, Serikawa M et al. Preoperative biliary drainage in cases of borderline resectable pancreatic cancer treated with neoadjuvant chemotherapy and surgery. Gastroenterol Res Pract 2016; 2016: 7968201

[13] Kubota K, Sato T, Watanabe $S$ et al. Covered self-expandable metal stent deployment promises safe neoadjuvant chemoradiation therapy in patients with borderline resectable pancreatic head cancer. Digest Endosc 2014; 26: 77-86

[14] Heneghan R, Rose J, Alseidi A et al. A comparative analysis of plastic versus metal endoscopic biliary stents in borderline resectable pancreatic cancer patients undergoing extended neoadjuvant chemotherapy. Gastroenterology 2013; 144: S1129

[15] Adams MA, Anderson MA, Myles JD et al. Self-expanding metal stents (SEMS) provide superior outcomes compared to plastic stents for pancreatic cancer patients undergoing neoadjuvant therapy. J Gastrointest Oncol 2012; 3: 309-313

[16] Nakamura K, Sho M, Akahori T et al. A comparison between plastic and metallic biliary stent placement in patients receiving preoperative neoadjuvant chemoradiotherapy for resectable pancreatic cancer. World J Surgery 2019; 43: 642-648

[17] Gardner TB, Spangler CC, Byanova KL et al. Cost-effectiveness and clinical efficacy of biliary stents in patients undergoing neoadjuvant therapy for pancreatic adenocarcinoma in a randomized controlled trial. Gastrointest Endosc 2016; 84: 460-466

[18] Ilic M, Ilic I. Epidemiology of pancreatic cancer. World J Gastroenterol 2016; 22: 9694-9705

[19] Barkun AN, Adam V, Lu Y et al. Using hemospray improves the costeffectiveness ratio in the management of upper gastrointestinal nonvariceal bleeding. J Clin Gastroenterol 2018; 52: 36-44

[20] Barkun AN, Adam V, Martel M et al. Cost-effectiveness analysis: stress ulcer bleeding prophylaxis with proton pump inhibitors, $\mathrm{H} 2$ receptor antagonists. Value Health 2013; 16: 14-22

[21] Chen YI, Barkun AN, Adam V et al. Cost-effectiveness analysis comparing lumen-apposing metal stents with plastic stents in the management of pancreatic walled-off necrosis. Gastrointest Endosc 2018; 88: $267-276$
[22] Karim S, Zhang-Salomans ], Biagi J] et al. Uptake and effectiveness of FOLFIRINOX for advanced pancreatic cancer: a population-based study. Clin Oncol (R Coll Radiol) 2018; 30: e16-e21

[23] Neumann PJ, Sanders GD, Russel LB et al. Cost-effectiveness in health and medicine. 2nd ed. New York, NY: Oxford University Press; 2017

[24] Almadi MA, Barkun A, Martel M. Plastic vs. Self-expandable metal stents for palliation in malignant biliary obstruction: a series of metaanalyses. Am J Gastroenterol 2017; 112: 260-273

[25] Almadi MA, Barkun JS, Barkun AN. Stenting in malignant biliary obstruction. Gastrointest Endosc Clin North Am 2015; 25: 691-711

[26] Crippa S, Cirocchi R, Partelli $S$ et al. Systematic review and meta-analysis of metal versus plastic stents for preoperative biliary drainage in resectable periampullary or pancreatic head tumors. Europ J Surg Oncol 2016; 42: 1278-1285

[27] Liu P, Lin H, Chen Y et al. Comparison of metal and plastic stents for preoperative biliary drainage in resectable and borderline resectable periampullary cancer: a meta-analysis and system review. J Laparoendosc Adv Surg Techniq 2018; 28: 1074-1082

[28] Walter D, van Boeckel PG, Groenen M] et al. Cost efficacy of metal stents for palliation of extrahepatic bile duct obstruction in a randomized controlled trial. Gastroenterology 2015; 149: 130-138

[29] Dumonceau JM, Tringali A, Papanikolaou IS et al. Endoscopic biliary stenting: indications, choice of stents, and results: European Society of Gastrointestinal Endoscopy (ESGE) Clinical Guideline - Updated October 2017. Endoscopy 2018; 50: 910-930

[30] Nakai Y, Isayama H, Wang HP et al. International consensus statements for endoscopic management of distal biliary stricture. J Gastroenterol Hepatol 2020; 35: 967-979

[31] Eloubeidi MA, Decker GA. ASGE Standards of Practice Committee. et al. The role of endoscopy in the evaluation and management of patients with solid pancreatic neoplasia. Gastrointest Endosc 2016; 83: $17-28$

[32] Kulkarni NM, Soloff EV, Tolat PP et al. White paper on pancreatic ductal adenocarcinoma from society of abdominal radiology's diseasefocused panel for pancreatic ductal adenocarcinoma: Part I, AJCC staging system, NCCN guidelines, and borderline resectable disease. Abdominal Radiol 2020; 45: 716-728

[33] Pan L, Fang J, Tong $C$ et al. Survival benefits of neoadjuvant chemo (radio)therapy versus surgery first in patients with resectable or borderline resectable pancreatic cancer: a systematic review and metaanalysis. World J Surg Oncol 2019; 18: 1-13

[34] Nennstiel S, Tschurtschenthaler I, Neu B et al. Management of occluded self-expanding biliary metal stents in malignant biliary disease. Hepatobil Pancreat Dis Int 2018; 17: 49-54

[35] Woods B, Revill P, Sculpher M et al. Country-level cost-effectiveness thresholds: initial estimates and the need for further research. Value Health 2016; 19: 929-935 